\title{
Haplotype analysis of the $X$ chromosome in patients with Turner syndrome in order to verify the possible effect of imprinting on selected symptoms
}

\author{
Petr Vrtel ${ }^{a}$, Radek Vrtel ${ }^{\mathrm{a}}$, Eva Klaskova ${ }^{\mathrm{b}}$, Dita Vrbicka ${ }^{\mathrm{a}}$, Katerina Adamova ${ }^{\mathrm{a}}$, Jan Pavlicekc, Vaclav Hana ${ }^{\mathrm{d}}$, Vaclav Hana Jr. ${ }^{\mathrm{d}}$, \\ Ondrej Soucek ${ }^{\mathrm{e}}$, Veronika Stara', Jan Lebl ${ }^{\mathrm{f}}$, Marta Snajdrova ${ }^{\mathrm{e}}$, Jirina Zapletalovaa ${ }^{\mathrm{b}}$, Tomas Furst ${ }^{\mathrm{g}}$, Sabina Kapralova ${ }^{\mathrm{b}}$, \\ Zdenek Tauberh, Eva Krejcirikova a, Marketa Routilova a, Julia Stellmachovaa ${ }^{a}$, Radek Vodicka ${ }^{\mathrm{a}}$, Martin Prochazka ${ }^{\mathrm{a}}$
}

\begin{abstract}
Aims. Turner syndrome is the only chromosome monosomy that is postnatally compatible with life. The reported incidence of TS is 1 in 2500 liveborn girls. The phenotype of these girls is highly variable, with cardiac abnormalities being life-threatening defects. The aim of the study was to reveal the possible influence of the parental origin of the $X$ chromosome in these patients on a selected phenotype that is associated with Turner syndrome. Selected symptoms and parameters were: a bicuspid aortic valve, aortic coarctation, lymphoedema, pterygium colli, coeliac disease, thyroiditis, otitis media, diabetes mellitus 2 , renal abnormalities, spontaneous puberty, and IVF.

Methods. The $X$ chromosome haplotype was determined for a group of $45, X$ patients verified by native FISH. A molecular diagnostic method based on the detection of different lengths of $X$ chromosome-linked STR markers using the Argus X-12 QS kit was used to determine the X haplotype.

Results. Our results, analysed by Fisher's exact (factorial) test, suggest independence between the maternal/paternal origin of the inherited $X$ chromosome and the presence of the anomalies that were studied $(P=1$ to $P=0.34)$.

Conclusion. In the group of $45, \mathrm{X}$ patients, who were precisely selected by means of the native FISH method, no correlation was demonstrated with the parental origin of the $\mathrm{X}$ chromosome and the observed symptom.
\end{abstract}

Key words: Turner syndrome, karyotype, phenotype, haplotype, chromosome X origin, imprinting

Received: October 1, 2020; Revised: November 18, 2020; Accepted: November 25, 2020; Available online: January 12, 2021 https://doi.org/10.5507/bp.2020.060

(c) 2022 The Authors; https://creativecommons.org/licenses/by/4.0/

${ }^{a}$ Department of Medical Genetics, Faculty of Medicine and Dentistry, Palacky University Olomouc and University Hospital Olomouc, Czech Republic

${ }^{b}$ Department of Paediatrics, Faculty of Medicine and Dentistry, Palacky University Olomouc and University Hospital Olomouc, Czech Republic

'Department of Paediatrics and Neonatal Care, Faculty of Medicine, University of Ostrava, Ostrava, Czech Republic

d3rd Department of Medicine - Department of Endocrinology and Metabolism, 1st Faculty of Medicine, Charles University in Prague, Czech Republic

${ }^{e}$ Department of Paediatrics, Motol University Hospital, Prague, Czech Republic

${ }^{f}$ Department of Paediatrics, 2nd Faculty of Medicine, Charles University in Prague, Czech Republic

${ }^{9}$ Department of Mathematical Analysis and Applications of Mathematics, Faculty of Science, Palacky University Olomouc, Czech Republic ${ }^{h}$ Department of Histology and Embryology, Palacky University Olomouc and University Hospital Olomouc, Czech Republic

Corresponding author:Radek Vrtel, e-mail:vrtel@fnol.cz

\section{INTRODUCTION}

Turner syndrome (TS), the only chromosomal monosomy postnatally compatible with life, has an incidence of approximately 1 in 2500 liveborn girls. TS is characterized by either the complete or partial loss of one copy of the $\mathrm{X}$ chromosome.

Most often, in $50 \%$ of cases, we encounter a $45, \mathrm{X}$ karyotype, $20-30 \%$ of the mosaic karyotype (45,X and at least one other cell line), and the rest of the cases are various structural aberrations of the $\mathrm{X}$ chromosome ${ }^{1}$.

Up to $99 \%$ of foetuses affected by this aneuploidy are spontaneously aborted before the 28th week of pregnancy. A $45, \mathrm{X}$ karyotype is observed in $1 \%$ to $2 \%$ of pregnancies, $10 \%$ of aborted foetuses, and $1 \%$ of newborns. The reason why exactly $1 \%$ of such affected foetuses survive without significant somatic abnormalities could be explained by the hypothesis of hidden mosaicism, where a cell line with all or part of the second sex chromosome is present ${ }^{2,3}$. Age at diagnosis is highly variable, from prenatal to adulthood.

Prenatally, foetal oedema, increased nuchal translucency, cystic hygroma, left heart abnormalities, and renal abnormalities may be present in the foetus. In the neonatal period, $20-30 \%$ of girls are diagnosed with characteristic lymphoedema, pterygium colli, heart defects (coarctation, hypoplastic left heart), a low-set hairline, or low-set ears. About $35 \%$ of cases are diagnosed in childhood as a result of a delay in the growth of the $<10$ percentile for a given age.

In adolescence and adulthood, patients experience the absence of breast development, menarche, primary/ secondary amenorrhoea, recurrent otitis media, cubitus valgus, pterygium colli, nail hypoplasia, shortening of the fourth metacarpus, or hearing loss. In connection with 
psychiatric disorders, these girls are described as shy and often suffering from social anxiety. Intelligence is usually normal, but patients with TS have a 1.7-fold higher incidence of depression than in the general population. In general, these patients are also more likely to suffer from autism spectrum disorder and depression. States of depression and anxiety can be caused by hormonal deficiency and subsequently also by hormonal therapy. Poor social inclusion of patients can also be an important factor in the onset of psychological problems ${ }^{4,5}$. The variability of the phenotype is based on the parental origin of the X chromosome, level of cell mosaicism, imprinting, and mutations of the $\mathrm{X}$ chromosome. Patients with a 45,X karyotype usually have more clinical manifestations compared to mosaic patients s,6,7 $^{4}$.

The main life-threatening phenotype in TS is congenital heart defects, with a prevalence of $17-50 \%$, with the highest incidence in a 45,X karyotype. The most common of these are the bicuspid aortic valve - almost $30 \%$ - and aortic coarctation in approximately $12 \%$ of women with TS. Very often, we also encounter hypoplasia of the left heart and anomalies of the pulmonary veins ${ }^{4,8-10}$.

The group of patients with the same karyotype is very variable in its phenotypic traits. A possible explanation is the effect of imprinting. The origin of the $\mathrm{X}$ chromosome is mostly maternal, $68-85 \%$. This condition indicates a defect during spermatogenesis in which the paternal $\mathrm{X}$ chromosome is lost ${ }^{11-16}$.

The main goal of this work was to correlate the haplotype of the $\mathrm{X}$ chromosome and the presence of a selected abnormality and the possible influence of in-vitro fertilization (IVF). The analysis will be related to patients with a cytogenetically confirmed pure line 45,X karyotype, verified by fluorescence in situ hybridization (FISH) on native blood.

\section{MATERIALS AND METHODS}

The present work is a multicentre study; the patients come from University Hospital Olomouc, the University Hospital in Ostrava, the First Faculty of Medicine, Charles University and General University Hospital in Prague, the Second Faculty of Medicine, Charles University in Prague, and Motol General and University Hospital in Prague. All the patients' data was shared in a central database, Clindata, informed consent of patients was provided.

For this study only patients who had a 45,X karyotype confirmed by FISH from native blood samples were included. A cohort of 55 patients and their parents was selected for haplotype analysis and subsequent correlation with the selected phenotype. All the patients were precisely karyotyped and verified by native FISH on 250 interphase nuclei.

The primary biological material for the DNA analysis was $9 \mathrm{~mL}$ of peripheral blood collected in EDTA tubes. Smears of buccal mucosa cells were taken from the parents using sterile brushes, which were deposited in paper envelopes after drying. A different type of primary mate- rial was chosen because of the priority determination of the karyotype in patients with TS, for whom peripheral blood collection was necessary; in the case of the parents this procedure was not indicated. Thus, the haplotype was tested in 50 families of patients with TS.

DNA was isolated from peripheral blood by the Miller method, which allows sufficient DNA of the necessary quality to be obtained for further analysis. Isolation using a commercial QIAamp DNA Mini Kit (www.qiagen. com) was chosen to isolate cells from the buccal mucosa.

The Investigator Argus X-12 QS kit (www.qiagen.com), which is based on the examination of a polymorphism of short tandem repeats (STR markers), was chosen to determine the $\mathrm{X}$ chromosome haplotype. It contains 12 markers from the $\mathrm{X}$ chromosome, a qualitative marker, amelogenin, and a control marker from chromosome 21. Alleles of individual markers from the X chromosome can also be quantified according to the proportion of relative fluorescence units (RFU), which allows the predominant $\mathrm{X}$ haplotype in mosaic TS to be determined.

The reaction mix was optimized for a total reaction volume of $8.33 \mu \mathrm{Ll}$. (2.5 FMl FMR 2.0, $0.83 \mu \mathrm{L}$ primer mix and $5 \mu \mathrm{L}$ DNA/PCR $\mathrm{H}_{2} \mathrm{O}$ ). The input DNA concentration to the reaction was adjusted to $0.5 \mathrm{ng} / \mu \mathrm{L}$, which was first measured on a spectrophotometer, and then verified on a Qubit fluorimeter using dsDNA HS Assay kit (www.thermofisher.com). PCR was performed in a BioRad C1000 thermocycler with the recommended profile for the kit that was applied. The samples were analysed on a 3130 Genetic Analyzer (Applied Biosystems); the evaluation was performed using the GeneScan software (Applied Biosystems).

\section{Phenotyping}

To analyse the possible phenotype/haplotype relationship of the X chromosome, the TS-related phenotypes that were clinically evaluated in our cohort of TS patients and are more common in TS patients compared to the female population were selected. For heart defects we selected a bicuspid aortic valve and aortic coarctation. We also focused on the phenotype that is often observed in TS: lymphoedema, pterygium colli, coeliac disease, thyroiditis, otitis media, diabetes mellitus 2, renal abnormalities, spontaneous puberty, and patients born after IVF.

\section{Statistical analyses}

For the statistical evaluation of a possible relationship between the phenotype and parental origin of the chromosome, Fisher's exact (factorial) test was used.

The null hypothesis was no difference between the proportion of maternal or paternal X chromosome in the phenotypic trait that was studied.

\section{RESULTS}

On the basis of the results of the karyotype analysis verified by native FISH on 250 interphase nuclei, 55 patients and their parents were selected for haplotype analysis and subsequent correlation with the selected 
phenotype. Because of the absence of parental biological material for DNA analysis, the cohort was reduced to 50 patients. These were predominantly 45,X (43 patients) and seven patients with a small proportion of mosaic (1, $4,5,5,13,15$, and 27 respectively from 250 interphase nuclei, i.e. $45, \mathrm{X} / 46, \mathrm{XX}$ with a small $46, \mathrm{XX}$ cell line proportion up to $10.8 \%$ ). Analysis with the Argus X-12 QS kit revealed a dominant representation of the maternal haplotype of the $\mathrm{X}$ chromosome (Xm) in $35 \mathrm{TS}$ patients (70\%). The paternal origin of the $\mathrm{X}$ chromosome $(\mathrm{Xp})$ was determined in 15 TS patients $(30 \%)$. The collected data is summarized in Table 1.

Our results suggest an absence of any dependence between the maternal/paternal origin of the inherited $\mathrm{X}$ chromosome and the presence of the anomalies that were studied ( $P=1$ to $P=0.34$ ).

As regards the presence of the given abnormalities in our cohort in comparison with the published incidence in TS patients, we revealed similar data. An exception is the incidence of renal defects, which in our study was recorded in $16 \%$ of the patients, compared to $30 \%$ reported in the cohort in the literature. There is a discrepancy in the presence of type 2 diabetes mellitus, which was not observed in the patients in our group compared to the general population. However, the results may be skewed by the size of our cohort of patients.

For a patient born after IVF, we do not have literature data for comparison, but we did not find any correlation with the phenotype.

\section{DISCUSSION}

Our goal was the precise selection of $45, \mathrm{X}$ patients using the native FISH method. The main reason is the degree of expression of the symptoms occurring in TS. The recent work of Tuke et al. ${ }^{7}$ states that clinical management should be aimed primarily at $45, \mathrm{X}$ patients whose clinical manifestation may be severe. In a given population study, more than 244,000 women from the UK Biobank were tested by means of a single-nucleotide polymorphism array and 30 women with 45,X, 186 with 45,X/46,XX, and 110 women with the 47,XXX karyotype were identified. The main take-home message was that mosaic patients often do not require the recommended intervention and the level of mosaicism is an important clinical indicator of the features and complications of TS. Surprisingly, in this subgroup there was no evidence of increased risk of cardiac complications. Additionally, this data suggests a usually normal reproductive lifespan or fertility if TS had two X chromosomes over $20 \%$ of cells.

It is known that the loss of the short arm of the $\mathrm{X}$ chromosome leads to the development of the TS phenotype. The work of Bondy et al. ${ }^{10}$ points out the high prevalence of bicuspid aortic valve and coarctation of the aorta in subjects missing just the short arm of the $\mathrm{X}$ chromosome, which indicates that haploinsufficiency of linked genes contributes to defective aortic development in TS. The association of haploinsufficiency of the SHOX gene with the TS phenotype (skeletal anomalies and short stature) has been demonstrated ${ }^{4,8}$.

The literature describes a relatively variable phenotype in TS patients with a 45,X karyotype; a possible explanation is the effect of imprinting, i.e. the influence of the parental origin of the $\mathrm{X}$ chromosome.

Such a situation has been described on X-linked parent - origin effect on brain development and cognitive functioning. This effect was described on 45,X TS girls, where in $25 \mathrm{Xp}$ patients significantly better social cognition skills were described than in $55 \mathrm{Xm}$ TS. That suggested that a genetic locus for social cognition is imprinted and is not expressed from Xm (ref. ${ }^{17}$ ). A model organism - 39,X mouse - was used for a similar TS phenotype. An $\mathrm{X}$-linked imprinted effect was confirmed in the genes in mice which are responsible for cognitive behaviour ${ }^{18}$.

However, correlation studies for other features yield relatively discrepant conclusions. Chu et al. ${ }^{11}$ found a strong correlation between a child's height centile and the maternal height centile for $\mathrm{Xm}(P<0.01)$. They found a strong correlation between cardiac anomalies and $\mathrm{Xm}$, $(P<0.01)$ and neck webbing and $\mathrm{Xm}(P<0.05)$. No significant difference in terms of renal abnormalities was found. Sagi et al. ${ }^{13}$ provided their own multicentre study of 80 patients and a literature review. Their findings suggest some correlation in renal malformations for Xm patients $(P=0.030)$, while eye abnormalities were more prevalent in the Xp haplotype $(P=0.017)$, and some significance was attributed to lipids and overweight. No significant correlation between haplotype and cardiac abnormalities or neck webbing was found. Bondy et al. ${ }^{14}$ presented a

Table 1. Results of our TS cohort, haplotyping, presence of abnormality in subgroups.

\begin{tabular}{|c|c|c|c|c|c|c|c|c|c|c|c|c|}
\hline & & $\mathrm{CoA}$ & $\mathrm{BaV}$ & IVF & Lym & Pte & $\mathrm{Cel}$ & Thy & Oti & Dia 2 & Ren & $\mathrm{SpP}$ \\
\hline \multirow[t]{7}{*}{ Our } & Pater X & $15(1)$ & $15(9)$ & $14(1)$ & $15(10)$ & $14(3)$ & $15(1)$ & $15(5)$ & $15(11)$ & $15(0)$ & $15(2)$ & $14(2)$ \\
\hline & & $6.7 \%$ & $60 \%$ & $7.1 \%$ & $66.7 \%$ & $21.4 \%$ & $6.7 \%$ & $33.3 \%$ & $73.3 \%$ & - & $13.3 \%$ & $14.3 \%$ \\
\hline & Mater X & $35(3)$ & 35 (15) & $32(2)$ & 29 (14) & $32(6)$ & $35(1)$ & $35(8)$ & $35(21)$ & $34(0)$ & $35(6)$ & $32(4)$ \\
\hline & & $8.6 \%$ & $42.9 \%$ & $6.3 \%$ & $48.3 \%$ & $18.8 \%$ & $2.9 \%$ & $22.9 \%$ & $60 \%$ & - & $17.1 \%$ & $12.5 \%$ \\
\hline & $P$-value & 1 & 0.36 & 1 & 0.34 & 1 & 1 & 0.49 & 0.52 & 1 & 1 & 1 \\
\hline & Total & $50(4)$ & $50(24)$ & $46(3)$ & $44(24)$ & $46(9)$ & $50(2)$ & $50(13)$ & $50(32)$ & $49(0)$ & $50(8)$ & $46(6)$ \\
\hline & & $8 \%$ & $48 \%$ & $6.5 \%$ & $54.5 \%$ & $19.6 \%$ & $4 \%$ & $26 \%$ & $64 \%$ & - & $16 \%$ & $13 \%$ \\
\hline References & Prev. In TS & $7-14 \% 10,23$ & $14-34 \%{ }^{10,23}$ & & $25-57 \%^{23,24}$ & $25 \%^{23}$ & $8 \%^{23}$ & $15-30 \%$ & $60 \%{ }^{23}$ & $10 \%{ }^{23}$ & $28-40 \%$ & $20-30 \% 4$ \\
\hline
\end{tabular}

(Pater X, paternal origin of chromosome X; Mater X, maternal origin of chromosome X; CoA, aortic coarctation; BaV, bicuspid aortic valve; Lym, lymphoedema; Pte, pterygium colli; Cel, coeliac disease; Thy, thyroiditis; Oti, otitis media; Dia2, diabetes mellitus 2; Ren, renal abnormalities; $\mathrm{SpP}$, spontaneous puberty). Unfortunately, not all the centres evaluated the whole list of symptoms. The number of positive cases for a specific trait is given in parentheses. 
comprehensive study of 183 TS patients. They found no evidence of X-imprinting in terms of short stature or renal and cardiovascular abnormalities. The effect of X-linked imprinting was described in the case of growth hormone response and sensorineural hearing loss. The patients with Xm had a greater mean height gain than Xp patients. A similar situation occurs with regard to sensorineural hearing loss. According to Hamelin et al. ${ }^{16}$, TS with Xm were less likely $(P=0.04)$ to have a hearing disability than Xp ones.

However, these studies determine the karyotype by conventional karyotyping, or also included TS mosaics in the haplotype-phenotype correlation. We believe that the process of cell culture leads to preferential growth of the physiological 46,XX cell line. For this reason, we prefer native FISH to prove the real state of the cell lines in the patient's body. The use of karyotyping and FISH on cultured material may be affected by a preference for a physiological cell line over an aneuploidy which may distort the true state in the germ layer being examined. The inclusion of mosaics in the haplotype analysis can then skew the result. Support for our results can be found in the work of Denes et al. ${ }^{19}$, who in their group of patients repeated the FISH examination in TS patients after ten years and found a positive correlation between age and the percentage change in diploid cells, with an average increase of $5.7-13 \%$. The process of senescence can be compared to cell cultivation before cytogenetic examination.

An innovative approach was taken by Devernay et al. ${ }^{15}$, who excluded mosaicism in the participating patients by FISH analysis. Finally, they selected 180 patients with homogenous $45, \mathrm{X}$. The parental origin of the X chromosome was not associated with body growth or response to growth hormone. Our goal was excluding the possible influence of the effect of mosaicism on our results.

We focused on pure $45, \mathrm{X}$ patients and very minor mosaics $(45, \mathrm{X} / 46, \mathrm{XX}$ with a small $46, \mathrm{XX}$ cell line proportion up to $10.8 \%)$. In such a selected cohort we did not reveal a statistically significant effect of the parental haplotype of the $\mathrm{X}$ chromosome on the presence of the selected phenotypic parameters. Our results suggest no influence of the parental X chromosome haplotype on the presence of a bicuspid aortic valve, coarctation of the aorta, lymphoedema, pterygium colli, coeliac disease, IVF, thyroiditis, otitis media, diabetes mellitus 2, renal abnormalities, or spontaneous puberty. We can postulate that there is probably no effect of imprinting but for a definitive statement it is necessary to have a larger cohort of patients and evaluate more linking abnormalities or compare the results of $45, \mathrm{X}$ patients and patients with high levels of mosaicism.

Haplotype analysis in our cohort of TS families revealed a ratio of $\mathrm{Xm}(70 \%)$ and $\mathrm{Xp}$ (30\%) which corresponds to previous studies ${ }^{11-16}$.

Currently, new possibilities are offered by the technology of massively parallel or next-generation sequencing (NGS), which would also be suitable for the examination of patients with TS. In particular, it would expand the possibilities for the investigation of partial deletions and quantification of $\mathrm{X}$ chromosome mosaics. It would also allow Y sequences to be searched for, since the positive findings of the $\mathrm{Y}$ fragment are then an indication for preventive gonadectomy ${ }^{20,21}$. The literature indicates that the presence of any genetic material derived from the $\mathrm{Y}$ chromosome (which may not be captured by a karyotype) is associated with an increased risk of gonadoblastoma, an estimated risk of $7-10 \%$ (ref. $^{22}$ ).

\section{CONCLUSION}

In the group of $45, \mathrm{X}$ patients who were precisely selected by means of the native FISH method, no correlation was demonstrated between the parental origin of the $\mathrm{X}$ chromosome and the symptoms that were observed.

Acknowledgement: Supported by the programme project of the Ministry of Health of the Czech Republic with Reg. No. 17-29111A.

Author contributions: PV: first author, manuscript writing, haplotype analysis, statistic evaluation; RVr: corresponding author, project design, manuscript writing, haplotype analysis; EKl: project design, clinical evaluation; DV: karyotyping, FISH analysis; KA: karyotyping, FISH analysis; JP: clinical evaluation, sample collection; VH: clinical evaluation, sample collection; VHJr: clinical evaluation, sample collection; OS: clinical evaluation, sample collection; VS: clinical evaluation, sample collection; JL: clinical evaluation, sample collection; MS: clinical evaluation, sample collection; JZ: clinical evaluation, sample collection; TF: statistical analysis; MP: professional consultation; SK: clinical evaluation; ZT: professional consultation; EKr: laboratory DNA analysis; MR: laboratory cytogenetic analysis; JS: professional consultation; RVo: professional consultation.

Conflict of interest statement: The authors state that there are no conflicts of interest regarding the publication of this article.

\section{REFERENCES}

1. Sävendahl L, Davenport ML. Delayed diagnoses of Turner's syndrome: proposed guidelines for change. J Pediatr 2000;137(4):45559.

2. Hook EB, Warburton D. The distribution of chromosomal genotypes associated with Turner's syndrome: livebirth prevalence rates and evidence for diminished fetal mortality and severity in genotypes associated with structural X abnormalities or mosaicism. Hum Genet 1983;64(1):24-27.

3. Held KR, Kerber S, Kaminsky E, Singh S, Goetz P, Seemanova E, Goedde HW. Mosaicism in 45,X Turner syndrome: does survival in early pregnancy depend on the presence of two sex chromosomes? Hum Genet 1992; 88(3): 288-94.

4. Gonzalez L, Witchel SF. The patient with Turner syndrome: puberty and medical management concerns. Fertil Steril 2012;98(4):780-86.

5. Green T, Flash S, Reiss AL. Sex differences in psychiatric disorders: what we can learn from sex chromosome aneuploidies. Neuropsychopharmacology 2019;44(1):9-21.

6. Cameron-Pimblett A, La Rosa C, King TFJ, Davies MC, Conway GS. The Turner syndrome life course project: Karyotype-phenotype analyses across the lifespan. Clin Endocrinol 2017;87(5):532-38.

7. Tuke MA, Ruth KS, Wood AR, Beaumont RN, Tyrrell J, Jones SE, Yaghootkar H, Turner CLS, Donohoe ME, Brooke AM, Collinson MN, 
DipRCpath, Freathy RM, Weedon MN, Frayling TM, Murray A. Mosaic Turner syndrome shows reduced penetrance in an adult population study. Genet Med 2019;21(4):877-86.

8. Sybert VP, McCauley E. Turner's syndrome. N Engl J Med 2004;351(12):1227-38.

9. Abdelmoula NB, Abdelmoula B, Smaoui W, Trabelsi I, Louati R, Aloulou S, Aloulou W, Abid F, Kammoun S, Trigui K, Bedoui O, Denguir H, Mallek S, Ben Aziza M, Dammak J, Kaabi O, Abdellaou N, Turki F, Kaabi A, Kamoun W, Jabeur J, Ltaif W, Cheker K, Fourati $\mathrm{H}$, M'rabet S, Ben Ameur H, Gouia N, Nabil Mhiri M, Rebai T. Leftsided congenital heart lesions in mosaic Turner syndrome. Mol Gen Genomics 2018;293(2):495-501.

10. Bondy C, Bakalov VK, Cheng C, Olivieri L, Rosing DR, Arai AE. Bicuspid aortic valve and aortic coarctation are linked to deletion of the X chromosome short arm in Turner syndrome. J Med Genet 2013;50(10):662-65.

11. Chu CE, Donaldson MD, Kelnar CJ, Smail PJ, Greene SA, Paterson WF, Connor JM. Possible role of imprinting in the Turner phenotype. Med Genet 1994;31(11):840-42.

12. Tanriverdi N, Demirhan O, Karahan DS, Pazarbaşi A. Frequencies and distributions of sex chromosome abnormalities in females with the Turner phenotype: a long-term retrospective study in the southern region of Turkey. Turk J Med Sci 2017;47(5):1447-55.

13. Sagi L, Zuckerman-Levin N, Gawlik A, Ghizzoni L, Buyukgebiz A, Rakover Y, Bistritzer T, Admoni O, Vottero A, Baruch O, Fares F Malecka-Tendra W, Hochberg Z. Clinical Significance of the Parenta Origin of the X Chromosome in Turner Syndrome. J Clin Endocrinol Metab 2007;92(3):846-52.

14. Bondy CA, Matura LA, Wooten N, Troendle J, Zinn AR, Bakalov VK. The physical phenotype of girls and woman with Turner syndrome is not X imprinted. Hum Genet 2007;121(3-4):469-74.

15. Devernay M, Bolca D, Kerdjana L, Aboura A, Gérard B, Tabet AC, Benzacken B, Ecosse E, Coste J, Carel JC. Parental Origin of the X-Chromosome Does Not Influence Growth Hormone Treatment Effect in Turner Syndrome. J Clin Endocrinol Metab 2012;97(7):E1241-E1248.

16. Hamelin CE, Anglin G, Quigley CA, Deal CHL. Genomic Imprinting in Turner Syndrome: Effects on Response to Growth Hormone and on Risk of Sensorineural Hearing Loss. J Clin Endocrinol Metab 2006;91(8):3002-10.

17. Skuse DH, James RS, Bishop DVM, Coppin B, Dalton P, AamodtLeeper G, Bacarese-Hamilton M, Creswell C, McGurk R, Jacobs PA. Evidence from Turner's syndrome of an imprinted X-linked locus affecting cognitive function. Nature 1997;387:705-8.

18. Davies W, Isles A, Smith R, Karunadasa D, Burrmann $D$, Humby T, Ojarikre O, Biggin C, Skuse D, Burgoyne P, Wilkinson L. Xlr3b is a new imprinted candidate for X-linked parent-of-origin effects on cognitive function in mice. Nat Genet 2005;37(6):625-29.

19. Denes AM, Landin-Wilhelmsen K, Wettergren Y, Bryman I, Hanson $\mathrm{CH}$. The Proportion of Diploid 46,XX Cells Increases with Time in Women with Turner Syndrome-A 10-Year Follow-Up Study. Genet Test Mol Biomarkers 2015;19(2):82-87.

20. Bispo AVS, Burégio-Fronta P, Oliveira dos Santos L, Leal GF, Duarte AR, Araújo J, da Silva VC, Muniz MTC, LiehrT, Santos N. Y chromosome in Turner syndrome: detection of hidden mosaicism and the report of a rare $X ; Y$ translocation case. Reprod Fertil Dev 2014;26(8):1176-82.

21. Baer TG, Freeman CE, Cujar C, Mansukhani M, Singh B, Chen X, Abellar R, Oberfield SE, Levy B. Prevalence and Physical Distribution of SRY in the Gonads of a Woman with Turner Syndrome: Phenotypic Presentation, Tubal Formation, and Malignancy Risk. Horm Res Paediatr 2017:88(3-4):291-97.

22. Gravholt CH, Fedder J, Naeraa RW, Müller J. Occurrence of Gonadoblastoma in Females with Turner Syndrome and $Y$ Chromosome Material: A Population Study. J Clin Endocrinol Metab 2000;85(9):3199-3202.

23. Gravholt $\mathrm{CH}$, Andersen NH, Conway GS, Dekkers OM, Geffner ME, Klein KO, Lin AE, Mauras N, Quigley CA, Rubin K, Sandberg DE, Sas TCJ, Silberbach M, Soderstrom-Attila V, Stochholm K, van Alfenvan derValden JA, Woelfle J, Backeljauw PF; International Turner Syndrome Consensus Group. Clinical practice guidelines for the care of girls and women with Turner syndrome: proceedings from the 2016 Cincinnati International Turner Syndrome Meeting. Eur J Endocrionol 2017; 77: 1-G70.

24. Welsh J, Todd M. Incidence characteristics of lymphedema in Turner's syndorme. Lymphology 2006;39(3):152-53. 